\title{
Optogenetic Probing of Fast Glutamatergic Transmission from Hypocretin/Orexin to Histamine Neurons In Situ
}

\author{
Cornelia Schöne, ${ }^{1}$ Zhen Fang Huang Cao, ${ }^{1,2}$ John Apergis-Schoute, ${ }^{1}$ Antoine Adamantidis, ${ }^{3}$ Takeshi Sakurai, ${ }^{4}$ \\ and Denis Burdakov ${ }^{1}$ \\ ${ }^{1}$ Department of Pharmacology, University of Cambridge, Cambridge CB2 1PD, United Kingdom, ${ }^{2}$ Janelia Farm Research Campus, Ashburn, Virginia 20147, \\ ${ }^{3}$ Douglas Mental Health University Institute, McGill University, Department of Psychiatry, Montreal, Quebec H4H 1R2, Canada, and ${ }^{4}$ Department of \\ Molecular Neuroscience and Integrative Physiology, Faculty of Medicine, Kanazawa University, Kanazawa, Ishikawa 920-8640, Japan
}

Hypothalamic hypocretin/orexin (hcrt/orx) neurons coordinate sleep-wake cycles, reward seeking, and body energy balance. Neurochemical data suggest that hcrt/orx cells contain several transmitters, but what hcrt/orx cells release onto their projection targets is unknown. A major pathway by which hcrt/orx neurons are thought to promote arousal is through projections to tuberomammillary histamine (HA) neurons. To study the impact of the electrical activity in hcrt/orx cells on HA neurons, we genetically targeted the light-activated excitatory ion channel channelrhodopsin-2 (ChR2) to the plasma membrane of hcrt/orx cells, and performed patch-clamp recordings from HA cells in acute mouse brain slices. Stimulation of ChR2-containing fibers with millisecond flashes of blue light produced fast postsynaptic currents in HA neurons, with a high connection probability $(\approx 60 \%$ of HA cells were connected to $\approx 40 \%$ of hcrt/orx cells expressing ChR2). These inputs depended on tetrodotoxin-sensitive action potentials, had kinetics typical of glutamatergic responses mediated by AMPA receptors, were blocked by the AMPA receptor blocker CNQX, and displayed multiple forms of short-term plasticity (depression in $\approx 70 \%$ trials, facilitation in $\approx 30 \%$ trials, both often in the same cell). Furthermore, stimulation of hcrt/orx axons at physiological frequencies rapidly and reversibly increased action potential firing in HA cells, an effect that was abolished by blockade of AMPA receptors. These results provide the first functional evidence that hcrt/orx neurons are capable of fast glutamatergic control of their projection targets, and suggest that variations in electrical activity of hcrt/orx axons can induce rapid changes in long-range signals generated by HA neurons.

\section{Introduction}

Hypothalamic hypocretin/orexin (hcrt/orx) neurons project widely throughout the brain and orchestrate sleep-wake cycles, reward seeking, and body energy balance (de Lecea et al., 2006; Sakurai, 2007). Loss of hcrt/orx cells leads to narcolepsy and obesity (Nishino et al., 2000; Thannickal et al., 2000; Hara et al., 2001); their selective optogenetic or pharmacogenetic silencing induces slow-wave sleep, while their optogenetic or pharmacogenetic stimulation causes awakening (Adamantidis et al., 2007; Sasaki et al., 2011; Tsunematsu et al., 2011). How the endogenous firing of hcrt/orx cells regulates their projection targets is unclear, due to technical difficulty of selectively stimulating hrct/orx cell axons in situ. Functional studies of this issue are important because neurochemical data suggest that hcrt/orx neurons may contain both excitatory and inhibitory transmitters, such as hcrt/

\footnotetext{
Received Feb. 14, 2012; revised July 6, 2012; accepted July 12, 2012.

Author contributions: C.S. and D.B. designed research; C.S., Z.F.H.C., J.A.-S., and A.A. performed research; A.A. and T.S. contributed unpublished reagents/analytic tools; C.S. analyzed data; D.B. wrote the paper.

This work was funded primarily by the European Research Council (FP7 Grant to D.B.), and also by the Government of Japan through its "Funding Program for Next Generation of World-leading Researchers" (grant to T.S.). We are grateful to Dr. Scott Sternson for advice on adenoviral constructs.

Correspondence should be addressed to Dr. Denis Burdakov, Department of Pharmacology, University of Cambridge, Cambridge CB2 1PD, UK. E-mail: dib22@cam.ac.uk.

DOI:10.1523/JNEUROSCI.0706-12.2012

Copyright $\odot 2012$ the authors $\quad 0270-6474 / 12 / 3212437-07 \$ 15.00 / 0$
}

orx, dynorphin (Chou et al., 2001), glutamate (Torrealba et al., 2003; Henny et al., 2010), and GABA (Harthoorn et al., 2005).

To study the postsynaptic consequences of electrical activity in hcrt/orx cell axons, here we used recently developed optogenetic tools (Yizhar et al., 2011; Bernstein et al., 2012) for selective excitation of hcrt/orx cells within their endogenous neural network. We explored the effects of fast and selective optogenetic stimulation of hcrt/orx cell axons on one of their key projection targets: the histamine (HA) neurons in the tuberomammillary hypothalamus. HA neurons are innervated by hcrt/orx cell axons and express hcrt/orx type- 2 receptors, while HA signaling is important for arousal induced by exogenously applied hcrt/orx (Eriksson et al., 2001; Huang et al., 2001; Yamanaka et al., 2002). However, it is unknown how the physiological output (firing rate) of HA cells is affected by endogenous firing of hcrt/orx cells at physiological frequencies. By combining whole-cell patchclamp recordings from HA neurons with optogenetic stimulation of hcrt/orx cells in acute mouse brain slices, we asked whether hcrt/orx axons release fast transmitters, and whether changes in electrical activity of hcrt/orx cells can influence the firing rate of HA neurons.

\section{Materials and Methods}

Gene transfer. Animal procedures followed United Kingdom Home Office regulations. Adenoviruses with "FLEX-switch" channelrhodopsin-2 (ChR2) constructs (Fig. 1A) (Atasoy et al., 2008) were infused into lateral 
A
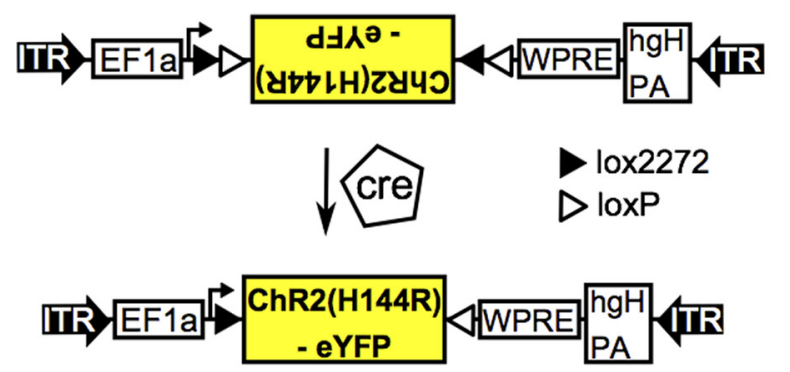

C

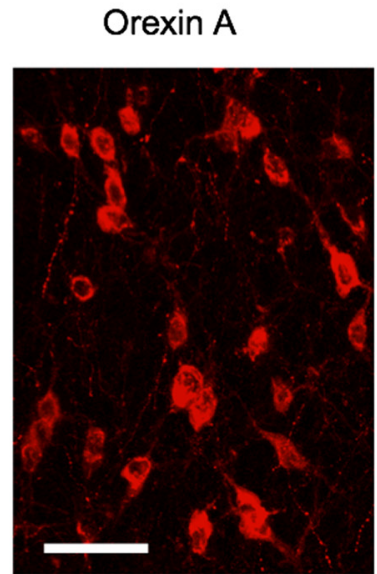

Cre-Recombinase

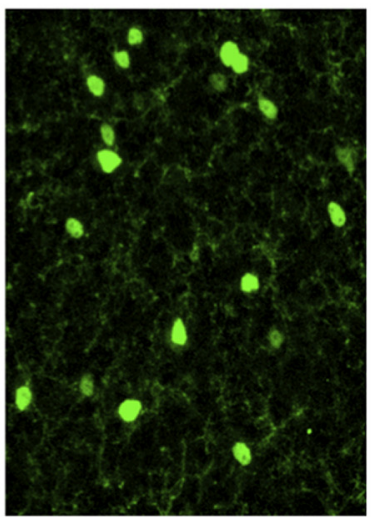

D
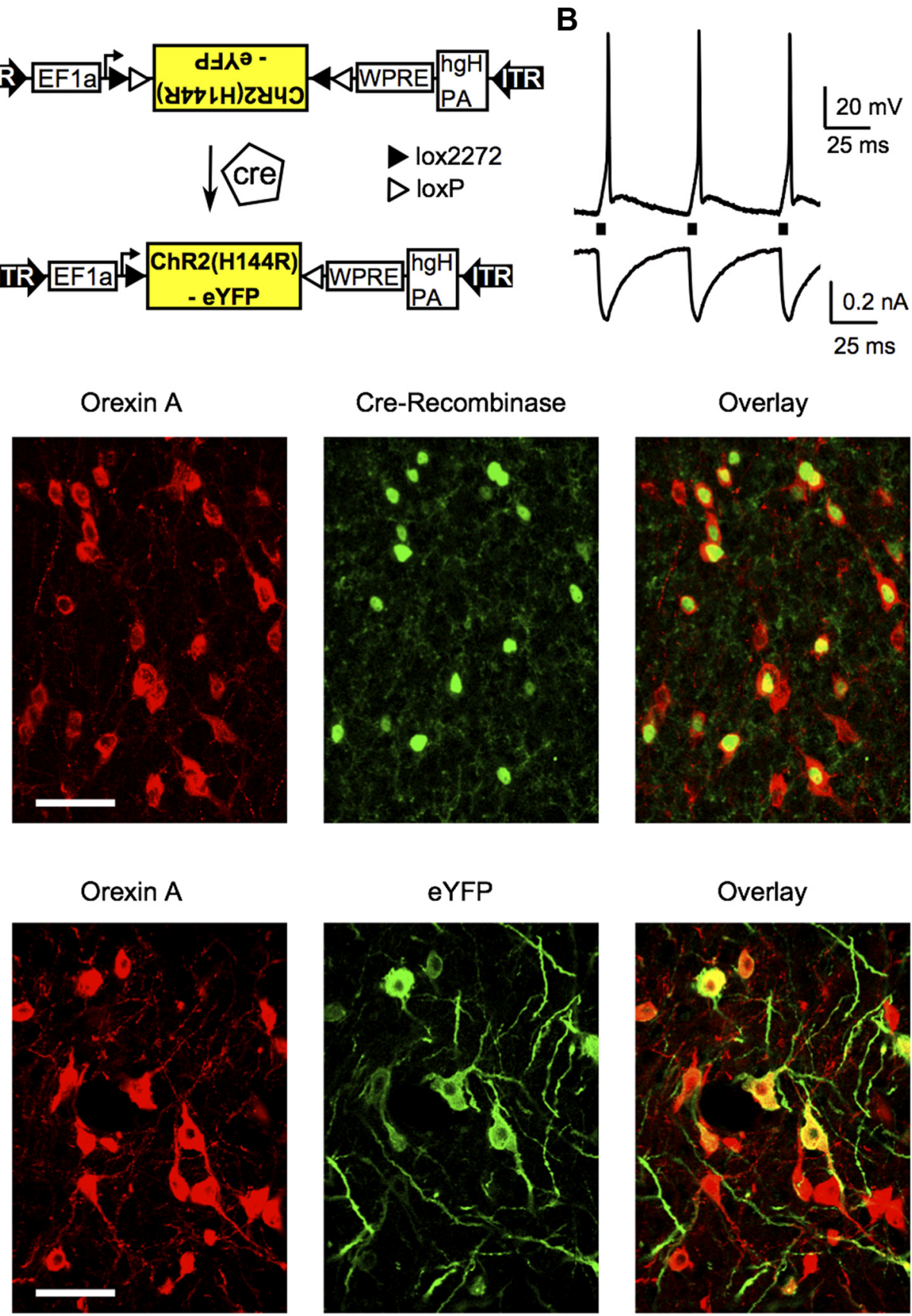

E

D-type

H-type
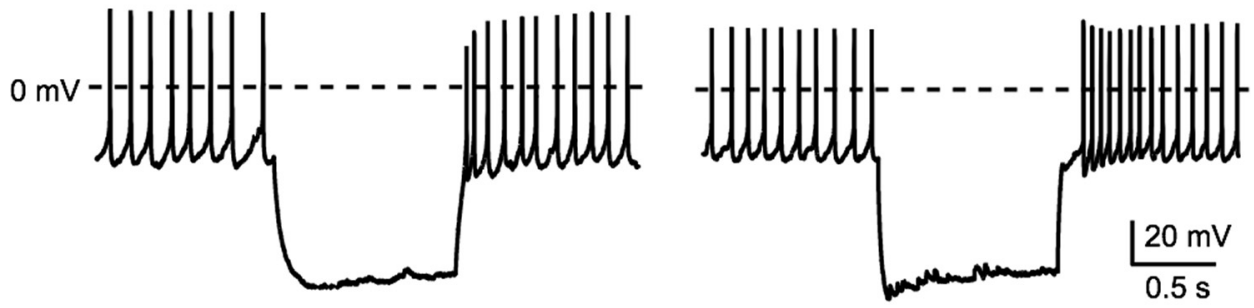

$0 \mathrm{pA}$
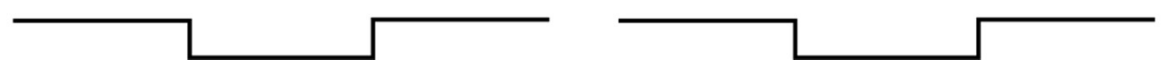

Figure 1. Optogenetic control of electrical activity of hcrt/orx cell membrane. A, ChR2-containing construct. When cre is present, the double-floxed inverted open reading frame of ChR2(H134R)eYFP is flipped, and loxP/lox2272 sites are inactivated. ITR, Inverted terminal repeat; EF1a, elongation factor $1 \alpha$ promoter; WPRE, WHP-post-transcriptional response (Figure legend continues.) 
hypothalamus (LH) of orexin-cre mice (Matsuki et al., 2009; Sasaki et al., 2011), bred in het-WT breeding pairs with C57BL/6J mice. The 4- to 6-week-old male and female mice were anesthetized with isofluorane and placed in a stereotaxic frame (David Kopf Instruments). A hole was drilled in the skull, and a borosilicate glass pipette (20-40 $\mu \mathrm{m}$ tip diameter) lowered into LH. Three $50 \mathrm{nl}$ injections $(75 \mathrm{nl} / \mathrm{min})$ were made as follows: -1.3 to $-1.4 \mathrm{~mm}$ from bregma; $\pm 0.9 \mathrm{~mm}$ from midline; and $-5.30,-5.15$, and $-5.00 \mathrm{~mm}$ from skull surface. The pipette was withdrawn 6 min after final injection (Adamantidis et al., 2007). Viral vectors were produced by Penn Vector Core (University of Pennsylvania, Philadelphia, PA). Titer of ChR2-tdtomato adenoviral construct (catalog \#AV-1-18917P, Vector Core; Addgene 18917) was $1.42^{*} 10^{13}$ genomic copies/ml. Titer of ChR2-eYFP adenoviral construct (catalog \#AV-120298P, Vector Core; Addgene 20298) was $1.5^{\star} 10^{12}$ genomic copies $/ \mathrm{ml}$.

Electrophysiology and photostimulation. Coronal slices containing $\mathrm{LH}$ or ventral tuberomammillary nucleus (TMN) were prepared 4-6 weeks postinjection (i.e., from 8- to 12 -week-old mice), as in Williams et al. (2011). Two-hundred fifty-micrometer-thick slices were cut using a Leica VT 1200 S vibratome in ice-cold ACSF (described under Chemicals and solutions, below). After $1 \mathrm{~h}$ recovery at $35^{\circ} \mathrm{C}$ in ACSF, slices were used for recordings. tdTomato or enhanced yellow fluorescent protein (eYFP) containing neurons were visualized, respectively, using an mCherry filter set (Chroma) or customized filter set (excitation 510/10 $\mathrm{nm}$, dichroic $520 \mathrm{~nm}$; emission 542/27 nm; Laser 2000). To stimulate ChR2, we used a LAMBDA DG-4 fast switcher (Sutter Instruments) with a xenon lamp and ET470/40 $\mathrm{nm}$ bandpass filter. Blue light $(\sim 10 \mathrm{~mW} /$ $\mathrm{mm}^{2}$ ) was delivered onto ChR2-containing axons around recorded cell via a $40 \times 0.8$ numerical aperture objective. Patch pipettes were made from borosilicate glass, and their tip resistances were 4-6 M $\Omega$ with K-gluconate solution (described under Chemicals and solutions, below). Whole-cell recordings were performed at $37^{\circ} \mathrm{C}$ using an EPC-10 amplifier and PatchMaster software (HEKA Elektronik). Only cells with access resistances of $<20 \mathrm{M} \Omega$ were used for analysis. Current signals were lowpass filtered at $3 \mathrm{kHz}$ and digitized at $10 \mathrm{kHz}$. Averaged data are presented as the mean \pm SEM. Analysis of postsynaptic currents (PSCs) was performed using Minianalysis (Synaptosoft) as in Schöne et al. (2011). Statistical significance was evaluated using ANOVA with Bonferroni's posttest, unless stated otherwise.

Chemicals and solutions. ACSF was gassed with $95 \% \mathrm{O}_{2}$ and $5 \% \mathrm{CO}_{2}$, and contained the following (in $\mathrm{mm}$ ): $125 \mathrm{NaCl}, 2.5 \mathrm{KCl}, 2 \mathrm{MgCl}_{2}, 2$ $\mathrm{CaCl}_{2}, 1.2 \mathrm{NaH}_{2} \mathrm{PO}_{4}, 21 \mathrm{NaHCO}_{3}, 1 \mathrm{D}$-(+)-glucose, $0.1 \mathrm{Na}^{+}$-pyruvate, and 0.4 ascorbic acid. For standard whole-cell recordings, pipettes were filled with intracellular solution containing the following (in $\mathrm{mM}$ ): 124 K-gluconate, $14 \mathrm{KCl}, 10 \mathrm{HEPES}, 1 \mathrm{EGTA}, 5 \mathrm{MgATP}, 0.3 \mathrm{Na}_{2} \mathrm{GTP}, 10$ $\mathrm{Na}_{2}$ phosphocreatine, $\mathrm{pH} 7.3$ with $\mathrm{KOH}$. All chemicals were from Sigma or Tocris Bioscience.

Immunostaining. To confirm the histaminergic nature of TMN neurons with electrical signatures of HA cells (Haas and Reiner, 1988; Haas et al., 1989), neurons were filled with biocytin (0.2\%, Tocris Bioscience) as in Schöne et al. (2011). We used streptavidin-Cy2 (1:500, Invitrogen) to detect biocytin. To detect adenosine deaminase, we used rabbit anti adenosine deaminase (Millipore Bioscience Research Reagents; 1:200) and goat anti-rabbit Alexa Fluor 555 (Invitrogen; 1:1000). Cy2 was excited with an argon laser at $488 \mathrm{~nm}$, and its fluorescence collected at $570-670 \mathrm{~nm}$ using a spectral detector (Olympus). Alexa Fluor 555 was excited with a diode-pumped solid-state laser at $559 \mathrm{~nm}$, and its fluorescence was collected at $570-670 \mathrm{~nm}$ using a spectral detector (Olympus).

\footnotetext{
(Figure legend continued.) element; hGH PA, human growth hormone polyadenylation signal. $\boldsymbol{B}$, Light flashes (black bars) evoke whole-cell currents (bottom trace, holding potential $=-60 \mathrm{mV}$ ) and action potentials (top trace) (representative example of $n=20$ cells). $C$, Colocalization of orexin-A and cre-recombinase-like immunoreactivities (representative example of $n=3$ brains). Scale bar, $50 \mu \mathrm{m}$. D, Colocalization of ChR2-eYFP with orexin-A-like immunoreactivities (representative example of $n=4$ brains). Scale bar, $50 \mu \mathrm{m}$. $\boldsymbol{E}$, Electrical fingerprints of ChR2-expressing cells showing D and H-type "signatures" of hert/orx cells (representative examples of $n=8$ cells).
}

To confirm the published specificity of cre-recombinase expression in orexin-cre mice (Matsuki et al., 2009), we immunostained $50 \mu \mathrm{m}$ cryostat LH sections, as in Karnani et al. (2011). Primary antibodies were rabbit anti-orexin A (Phoenix Pharmaceuticals; 1:250) and mouse anticre-recombinase (Millipore; 1:500). Secondary antibodies were goat anti-rabbit Alexa Fluor 647 (1:500) and anti-mouse Alexa Fluor 488 (1:1000) from Invitrogen. Alexa Fluor 488 and 647 signals were collected using BP525/50 nm and BP700/75 nm filters respectively. Orexinimmunoreactivity (IR) was detectable in $94 \pm 2 \%$ of cre-IR neurons in the $\mathrm{LH}$, while cre-IR was detectable in $58 \pm 5 \%$ of orexin-IR neurons ( $n=3$ animals, 1200 cells). Following viral transduction, orexin-IR was detectable in $86 \pm 2 \%$ of ChR2-FP cells, and ChR2-FP was detectable in $41 \pm 2 \%$ of orexin-IR cells ( $n=4$ animals, 1560 cells). This is consistent with specific expression of cre in hcrt/orx cells in this mouse line (Matsuki et al., 2009). Selective expression of ChR2-FP was further confirmed by observations of typical hcrt/orx cell electrical signatures in ChR2-FP cells (see Results).

\section{Results}

\section{Selective excitation of hcrt/orx cell membranes in acute brain slices}

In ChR2-containing hcrt/orx cells (identified by fluorescence and verified by immunostaining and electrical fingerprinting; see Materials and Methods) (Fig. $1 D, E$ ), flashing blue light robustly produced time-locked whole-cell currents (Fig. $1 \mathrm{~B}$; current amplitude at $-60 \mathrm{mV}$ was $686 \pm 150 \mathrm{pA}, n=9)$ and action potentials (Fig. $1 B ; n=20$ ). Flash durations of $1-5 \mathrm{~ms}$ and flash frequencies of $1-20 \mathrm{~Hz}$ (the physiological firing band for hcrt/orx cells in vivo; Lee et al., 2005; Mileykovskiy et al., 2005), produced time-locked action potentials in ChR2-containing neurons with $100 \%$ reliability (assessed using a 10 s flash train, $n=20$; Fig. $1 B$ ). LH neurons not containing ChR2 showed no responses to blue light ( $n=5$, data not shown), confirming that responses of ChR2-FP cells were not due to nonspecific photodamage. ChR2-expressing cells retained characteristic membrane potential dynamics of wild-type hcrt/orx cells (Williams et al., 2008; Schöne et al., 2011), such as typical postinhibitory rebounds and tonic firing at $4.7 \pm 1.4 \mathrm{~Hz}$ (Fig. $1 E ; n=8 / 8$ cells). Together, these data confirm that ChR2 enables selective and precise electrical control of hcrt/orx cell membrane without disrupting intrinsic properties of these cells.

\section{Detecting spike-mediated transmitter release from hcrt/orx axons onto HA neurons}

Expression of fluorescent ChR2 in hcrt/orx neurons produced a network of ChR2-containing axons in the TMN (Fig. 2 A). To test whether stimulation of these axons affects HA cells, we performed whole-cell recordings from TMN HA neurons while optically stimulating ChR2. Note that, although some of our TMN slices contained hcrt/orx neurons, successful stimulation and transmitter release from ChR2-containing axons do not require them to be connected to cell bodies (Petreanu et al., 2007). As in our previous studies (Williams et al., 2011), we identified HA neurons by: (1) large (20-30 $\mu$ m diameter) multipolar cell body; (2) hyperpolarization-activated depolarizing "sag" indicative of H-current expression; (3) prominent postinhibitory afterhyperpolarization; and (4) tonic firing at resting membrane potential (Fig. 2B) (Haas and Reiner, 1988; Haas et al., 1989). Immunolabeling confirmed that such TMN cells contained the HA cell marker adenosine-deaminase (Fig. $2 A ; n=3 / 3$ cells).

Optical stimulation of TMN slices containing ChR2 axons produced fast postsynaptic currents in HA cells (Fig. $2 C$; $n=$ $36 / 65$ cells). HA cells from slices that did not contain ChR2 axons did not show membrane responses to the light flashes $(n=10$, data not shown), confirming that light-triggered PSCs to HA cells 
A

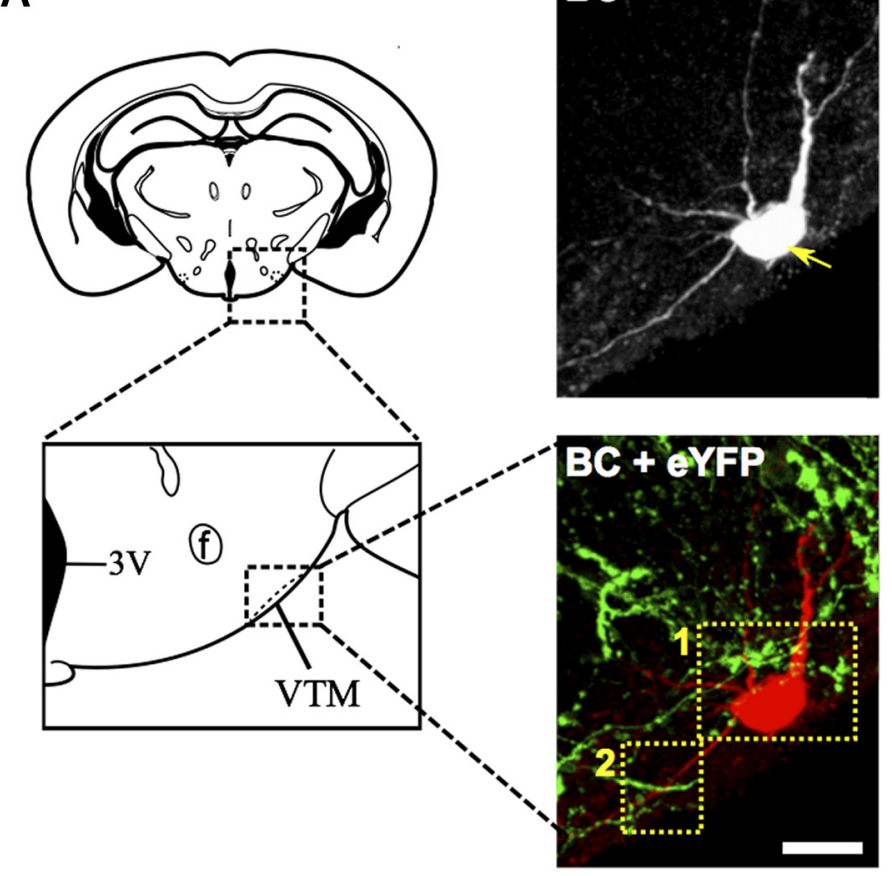

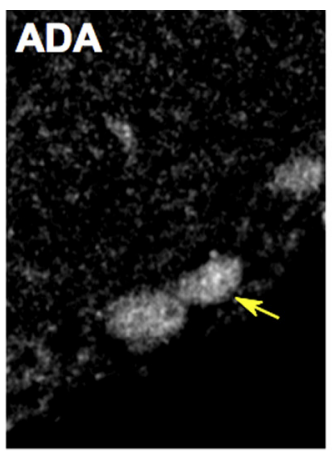
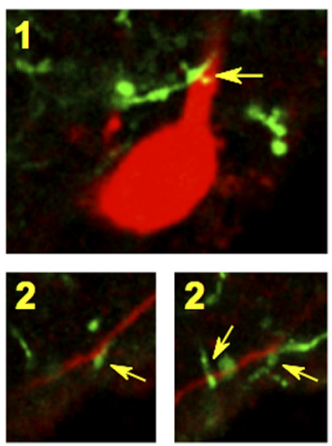

B

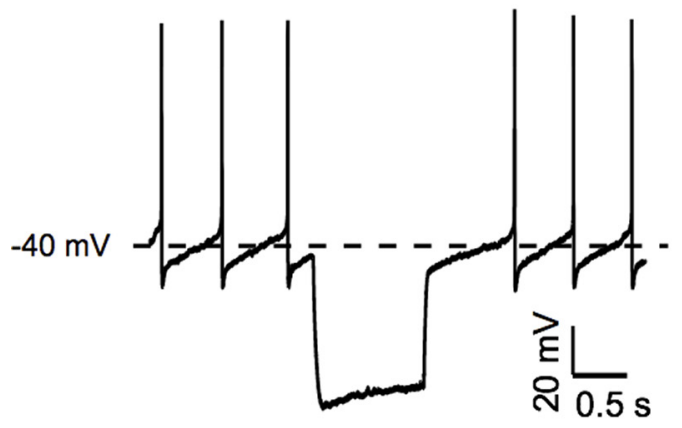

C

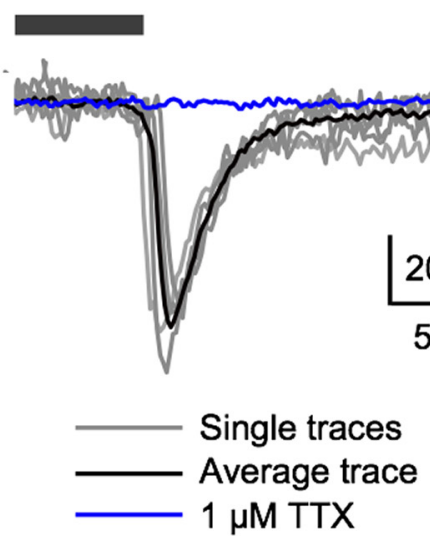

$0 \mathrm{pA}$

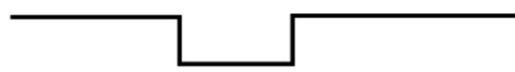

Figure 2. Spike-mediated transmitter release from hcrt/orx axons onto HA neurons. $\boldsymbol{A}$, Left, Coronal schematic at bregma $-2.3 \mathrm{~mm}$ showing ventral TMN (VTM). f, Fornix; $3 \mathrm{~V}$, third ventricle. Right, z-projections from confocal stacks. Top, biocytin (BC)-filled cell, colocalizing with ADA-like immunoreactivity (arrowed). Bottom right, Same cell as in top (red), overlaid with ChR2-eYFP fibers (green). Scale bar, $20 \mu \mathrm{m}$. Bottom left, Higher magnification of same cell showing single confocal planes, with fiber-cell appositions arrowed. Representative example of $n=10$ cells. $\boldsymbol{B}$, Typical electrical current-clamp fingerprint of an HA cell (representative example of $n=35$ cells). C, Fast PSC in an HA neuron upon ChR2 stimulation (light flash shown as black bar), and recorded at -60 $\mathrm{mV}$ (individual traces in gray, averages in black or blue), with and without tetrodotoxin (TTX). Representative example of $n=8$ cells.

are caused by ChR2. In ChR2-expressing slices, the delays between flash onset and PSCs ( $\approx 5$ ms; Figs. $2 C$, Fig. $3 B$ ) were consistent with previous studies using optogenetics to probe fast transmitter release (Atasoy et al., 2008; Tecuapetla et al., 2010). Tetrodotoxin completely abolished the light-triggered PSCs (Fig. $2 C ; n=8$ ), confirming that they were triggered by tetrodotoxinsensitive $\mathrm{Na}^{+}$spikes in the axon, rather than by unphysiological influx of $\mathrm{Ca}^{2+}$ through ChR2 (Nagel et al., 2003).

\section{Functional properties of fast transmission in hcrt/orx $\rightarrow$}

HA circuit

We next studied the kinetics, pharmacology, frequency dependence, and release probability of the optogenetically evoked PSCs in HA cells. The PSCs had amplitudes of $26.0 \pm 1.8 \mathrm{pA}$ and monoexponential decay time constants of $3.2 \pm 0.4 \mathrm{~ms}$ (Fig. $3 B$, see spread of values; $n=15$ ), consistent with PSCs mediated by glutamate AMPA receptors (Dingledine et al., 1999). Blockade of AMPA receptors with CNQX completely blocked the PSCs (Fig. $3 A ; n=12$ ), suggesting that axons originating from hcrt/orx neurons modulate HA cells via fast AMPA receptor-mediated synaptic transmission.

Current evidence indicates that hcrt/orx neurons fire $<20 \mathrm{~Hz}$ in vivo, but can be driven to fire up to $300 \mathrm{~Hz}$ in vitro (Li et al., 2002; Lee et al., 2005; Mileykovskiy et al., 2005). However, it is unknown which firing frequencies are optimal for controlling transmitter release. We thus optically stimulated hcrt/orx axons at different frequencies and quantified the success rate and total charge input of the glutamatergic PSCs in HA cells (Fig. 3C,D). The positive relationship between the effect of glutamate on the postsynaptic cell and the presynaptic stimulation frequency saturated above $5 \mathrm{~Hz}$ (Fig. $3 D$; $n=8-9$ per stimulation frequency). This was presumably in part because the success rate for PSC generation fell with stimulation frequency: with 
A

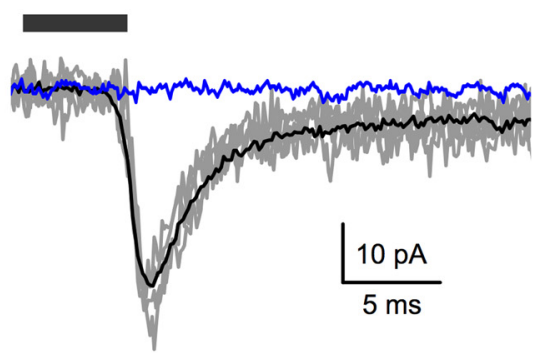

B

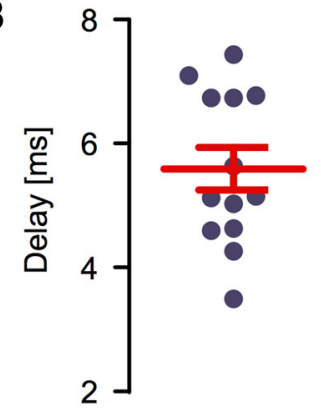

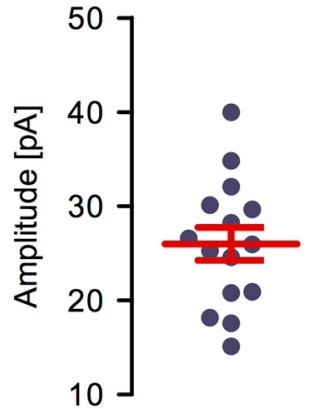

D
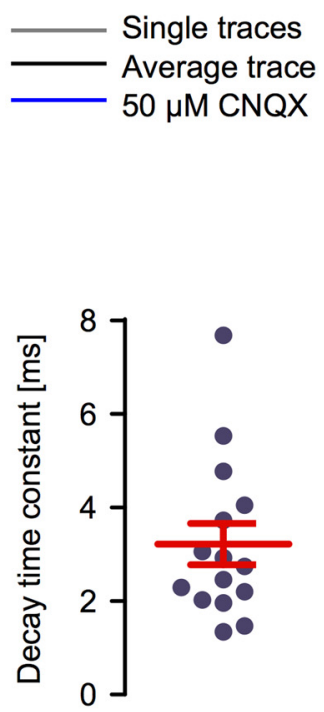

C

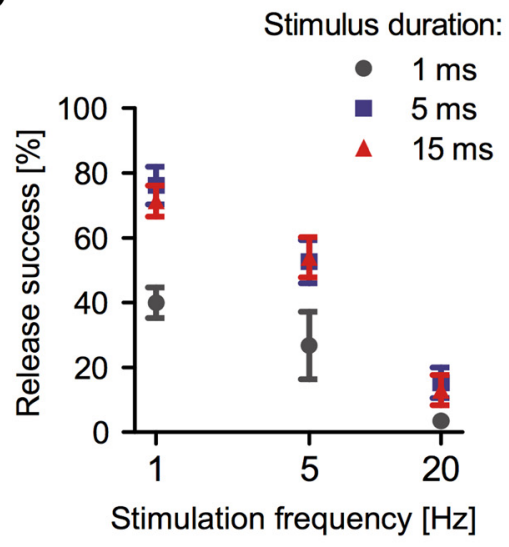

E

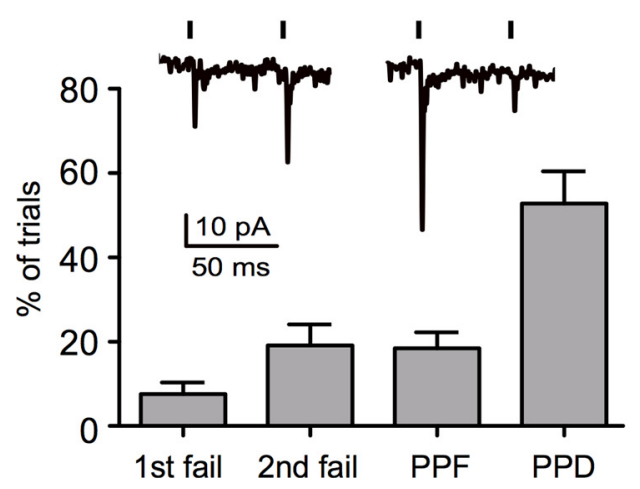

Stimulus duration:

- $5 \mathrm{~ms}$

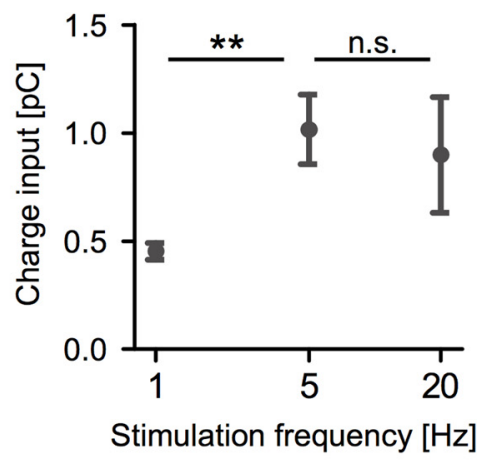

$\mathbf{F}$

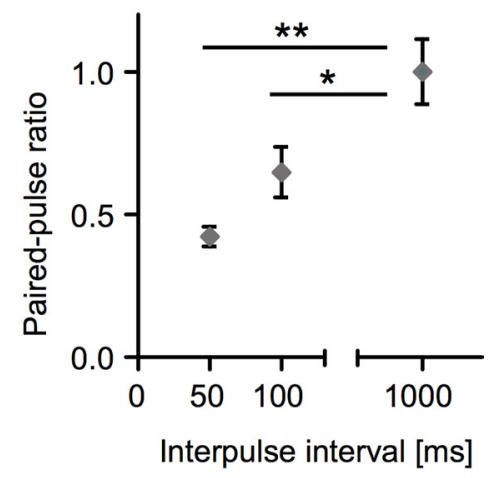

Figure 3. Pharmacological and biophysical properties of fast hcrt/orx $\rightarrow$ HA inputs. A, Optogenetically induced PSCs (black bar shows light stimulus) with and without CNQX (recordings at $-60 \mathrm{mV}$, individual responses are in gray, averages are in black or blue). Representative example of $n=12$ cells. $\boldsymbol{B}$, Properties of PSCs (black dots are means from individual cells obtained using $0.1 \mathrm{~Hz}$ stimulation; $n=15$ cells; population means \pm SEM are in red). C, Success rate of optogenetic stimulation to evoke PSCs during 10 s stimulus train. D, Total charge transfer in hcrt/orx $\rightarrow$ HA PSCs during a 10 s stimulus train (sum of charges of PSCs); $n=8-9$ cells per condition; ${ }^{* *} p<0.01 ;$ n.s. $=p>0.05$; Student's $t$ test. $E$, Short-term plasticity in hcrt/orx $\rightarrow$ HA PSCs. Examples of paired-pulse depression (PPD, top left trace) and paired-pulse facilitation (PPF, top right trace). Bar graph shows mean proportions of different types of responses in 10 cells (percentage of trials that failed to produce PSC on first or second flash are also shown). $\boldsymbol{F}$, Paired-pulse ratio at different interpulse intervals. ${ }^{*} p<$ $0.05 ;{ }^{* *} p<0.01$; one-way ANOVA with Bonferroni's post-test.

5 ms flashes, increasing flash frequency from 1 to $5 \mathrm{~Hz}$ to $20 \mathrm{~Hz}$ reduced success from $76 \pm 6 \%$ to $53 \pm 7 \%$ to $15 \pm 5 \%$, respectively. The effect of flash frequency on the success rate was significant (one-way ANOVA: $\left.F_{(2,22)}=26.17 ; p<0.001 ; n=8\right)$, as were the differences in success rate between 1 and $5 \mathrm{~Hz}\left(t_{(15)}=2.856 ; p<0.05\right)$ and 1 and $20 \mathrm{~Hz}\left(t_{(14)}=7.172 ; p<0.001\right)$. We also quantified the paired-pulse ratio of PSC amplitudes, a measure of short-term plasticity at central synapses (Dobrunz and Stevens, 1997). We observed both pairedpulse depression and facilitation, often in different trials from the same cell (Fig. 3E; $n=11$ ). However, on average each cell showed predominantly paired-pulse depression, with the mean paired-pulse ratio significantly $<1$ (Fig. $3 F$ ).

\section{Stimulation of hcrt/orx cell axons rapidly alters $\mathrm{HA}$ cell firing}

Finally, we investigated the impact of hort/ orx cell stimulation on the physiological output (firing rate) of HA cells. When HA cells were recorded in current-clamp with zero holding current, individual light flashes evoked clear membrane depolarizations (Fig. 4A; the amplitude of subthreshold depolarizations was $3.7 \pm 0.5$ $\mathrm{mV}$, from $n=8$ cells). After recording the HA cell membrane potential for $10 \mathrm{~s}$ without stimuli, we applied $5 \mathrm{~ms}$ light stimuli for $10 \mathrm{~s}$ at frequencies of $1-20 \mathrm{~Hz}$, and recorded for another $10 \mathrm{~s}$ to monitor recovery from the stimulus (Fig. $4 B$ ). In HA cells functionally connected to hcrt/orx axons (identified by first looking at optically evoked PSCs; Fig. 2C), stimulation frequency significantly affected HA cell firing (two-way ANOVA: $F_{(4,53)}=2.677$; $p>0.05 ; n=4-9$ per stimulation frequency). Compared with baseline, there was significant stimulation at $5 \mathrm{~Hz}\left(t_{(14)}=\right.$ $2.840 ; p<0.05 ; n=9), 10 \mathrm{~Hz}\left(t_{(14)}=\right.$ 4.061; $p<0.001 ; n=9)$, and $20 \mathrm{~Hz}$ $\left(t_{(11)}=4.232 ; p<0.001 ; n=6\right)$. In all stimulation conditions used here, the acceleration of HA cell firing was completely abolished by pharmacological blockade of AMPA receptors with CNQX (Fig. 4B; no differences between baseline and stimulation by two-way ANOVA and Bonferroni's post-test, $p>0.05$ in all cases; Fig. $4 C)$. This is consistent with voltage-clamp data (Fig. $3 A$ ), and shows that glutamate release is necessary for the electrical activity in hcrt/orx axons to be translated into changes in HA cell firing.

\section{Discussion}

The present study is the first direct demonstration that hcrt/orx cells can release 
glutamate under physiological conditions in situ. This suggests that the firing of hcrt/ orx cells can be translated into changes in their postsynaptic targets very rapidly (on a millisecond timescale), in addition to the much slower actions of neuropeptides produced by hcrt/orx cells ( $\mathrm{Li}$ and van den Pol, 2006).

We observed a high glutamatergic connection probability in the hcrt/orx $\rightarrow \mathrm{HA}$ circuit $(\approx 60 \%$ of HA cells received connections from $\approx 40 \%$ of hcrt/orx cells expressing ChR2). To the best of our knowledge, there are few studies of functional connectivity between neuronal types in subcortical circuits. Our data suggest that the hcrt/orx $\rightarrow$ HA circuit is robustly connected, similar to recent studies of cortical circuits where connection probabilities approach 100\% (Petreanu et al., 2007). In our analysis, the reduced release probability at increased presynaptic firing rates resulted in functional saturation of the hcrt/orx $\rightarrow$ HA connection above $\sim 5 \mathrm{~Hz}$ (Fig. 3C,D). Interestingly, this is consistent with the saturating relationship between hcrt/orx cell firing and arousal effects observed in vivo (Adamantidis et al., 2007). In the stimulation paradigms used here, blockade of AMPA receptors completely abolished the postsynaptic effect of hcrt/orx axon stimulation, suggesting that release of other transmitters was not sufficient to alter HA cell firing. The roles of other transmitters released by orx/hct cells in postsynaptic electrical responses remain to be determined.

The contribution of HA signaling to arousal caused by the activity of hcrt/orx cells has been a matter of recent debate. Arousal stimulated by exogenously applied hcrt/orx depends on HA signaling (Huang et al., 2001; Yamanaka et al., 2002), but arousal produced by optogenetic stimulation of endogenous hcrt/orx neurons persists in mice lacking histidine decarboxylase, the enzyme that produces HA (Carter et al., 2009). The latter finding does not detract from the potential physiological significance of our data, because (1) apart from HA, HA neurons contain many other transmitters such as GABA, galanin, enkephalin, thyrotropin-releasing hormone, and substance $\mathrm{P}$ (Haas et al., 2008), which could propagate hcrt/orx cell signals in the absence of HA; and/or (2) the glutamatergic drive to HA cells described in our study may contribute to processes distinct from the arousal outputs measured in the above studies (e.g., cognitive processing or the regulation of energy balance). It is also possible that in mice lacking HA, other arousal systems stimulated by hcrt/orx cells compensate, for example, the noradrenaline, serotonin, and acetylcholine systems (Peyron et al., 1998; Jones, 2003; Saper et al., 2005).

Glutamatergic signaling from hcrt/orx to HA neurons could be important because it offers a novel mechanism for contributing sufficiently fast EPSPs to allow transferring information from
B
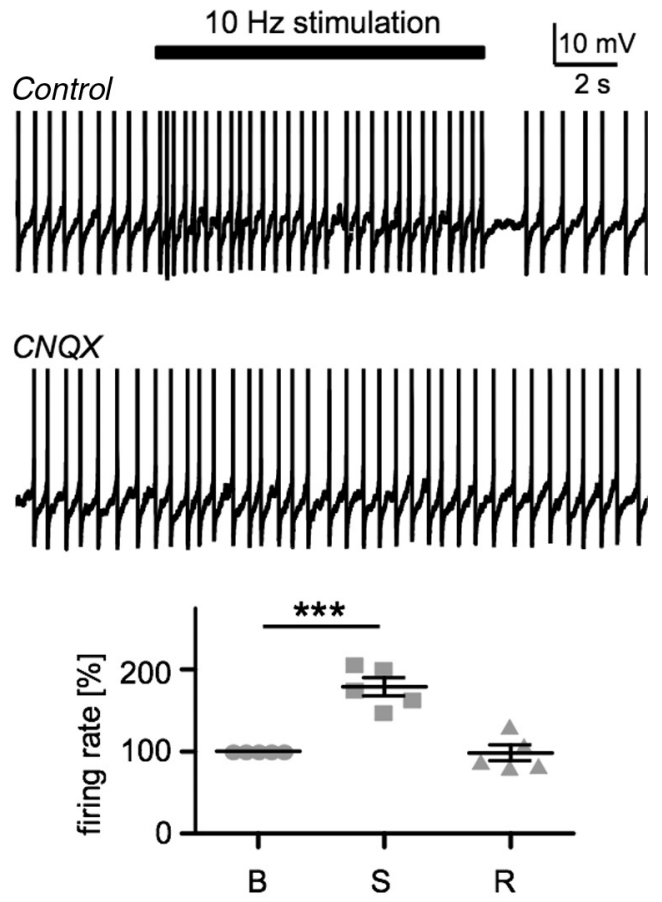

Figure 4. Optogenetic stimulation of hcrt/orx cell axons rapidly alters $\mathrm{HA}$ cell firing. $A$, Example membrane potential responses to a 5 ms flash (representative example of $n=8$ cells). $\boldsymbol{B}$, Example changes in HA cell firing induced by optical stimulation in the absence (top trace) and presence (bottom trace) of CNQX (representative example of $n=9$ cells). Action potentials are truncated the percentage change in firing, ${ }^{* * *} p<0.001$, one-way ANOVA followed by Bonferroni's post-test. $C$, Effects of different stimulation frequencies on firing rate in control and CNQX; $n=4-9$ per group. ${ }^{*} p<0.05$; ${ }^{* * *} p<0.001 ; n .5 .=p>0.05$, two-way ANOVA with Bonferroni's post-test.

transient spike bursts of hcrt/orx observed in vivo (Lee et al., 2005; Mileykovskiy et al., 2005). It may also potentially serve to synchronize the firing of HA cells and/or rapidly regulate plasticity in HA cell synapses. Of more general importance, our observations suggest that, in addition to their slow neuromodulatory role, hcrt/orx cell axons may rapidly alter brain function through fast glutamatergic transmission.

\section{References}

Adamantidis AR, Zhang F, Aravanis AM, Deisseroth K, de Lecea L (2007) Neural substrates of awakening probed with optogenetic control of hypocretin neurons. Nature 450:420-424.

Atasoy D, Aponte Y, Su HH, Sternson SM (2008) A FLEX switch targets channelrhodopsin-2 to multiple cell types for imaging and long-range circuit mapping. J Neurosci 28:7025-7030.

Bernstein JG, Garrity PA, Boyden ES (2012) Optogenetics and thermogenetics: technologies for controlling the activity of targeted cells within intact neural circuits. Curr Opin Neurobiol 22:61-71.

Carter ME, Adamantidis A, Ohtsu H, Deisseroth K, de Lecea L (2009) Sleep 
homeostasis modulates hypocretin-mediated sleep-to-wake transitions. J Neurosci 29:10939-10949.

Chou TC, Lee CE, Lu J, Elmquist JK, Hara J, Willie JT, Beuckmann CT, Chemelli RM, Sakurai T, Yanagisawa M, Saper CB, Scammell TE (2001) Orexin (hypocretin) neurons contain dynorphin. J Neurosci 21:RC168.

de Lecea L, Jones BE, Boutrel B, Borgland SL, Nishino S, Bubser M, DiLeone R (2006) Addiction and arousal: alternative roles of hypothalamic peptides. J Neurosci 26:10372-10375.

Dingledine R, Borges K, Bowie D, Traynelis SF (1999) The glutamate receptor ion channels. Pharmacol Rev 51:7-61.

Dobrunz LE, Stevens CF (1997) Heterogeneity of release probability, facilitation, and depletion at central synapses. Neuron 18:995-1008.

Eriksson KS, Sergeeva O, Brown RE, Haas HL (2001) Orexin/hypocretin excites the histaminergic neurons of the tuberomammillary nucleus. J Neurosci 21:9273-9279.

Haas HL, Reiner PB (1988) Membrane properties of histaminergic tuberomammillary neurones of the rat hypothalamus in vitro. J Physiol 399:633-646.

Haas HL, Greene RW, Reiner PB (1989) The brain histamine system in vitro. J Neurosci Methods 28:71-75.

Haas HL, Sergeeva OA, Selbach O (2008) Histamine in the nervous system. Physiol Rev 88:1183-1241.

Hara J, Beuckmann CT, Nambu T, Willie JT, Chemelli RM, Sinton CM, Sugiyama F, Yagami K, Goto K, Yanagisawa M, Sakurai T (2001) Genetic ablation of orexin neurons in mice results in narcolepsy, hypophagia, and obesity. Neuron 30:345-354.

Harthoorn LF, Sañé A, Nethe M, Van Heerikhuize JJ (2005) Multitranscriptional profiling of melanin-concentrating hormone and orexincontaining neurons. Cell Mol Neurobiol 25:1209-1223.

Henny P, Brischoux F, Mainville L, Stroh T, Jones BE (2010) Immunohistochemical evidence for synaptic release of glutamate from orexin terminals in the locus coeruleus. Neuroscience 169:1150-1157.

Huang ZL, Qu WM, Li WD, Mochizuki T, Eguchi N, Watanabe T, Urade Y, Hayaishi O (2001) Arousal effect of orexin A depends on activation of the histaminergic system. Proc Natl Acad Sci U S A 98:9965-9970.

Jones BE (2003) Arousal systems. Front Biosci 8:s438-s451.

Karnani MM, Apergis-Schoute J, Adamantidis A, Jensen LT, de Lecea L, Fugger L, Burdakov D (2011) Activation of central orexin/hypocretin neurons by dietary amino acids. Neuron 72:616-629.

Lee MG, Hassani OK, Jones BE (2005) Discharge of identified orexin/hypocretin neurons across the sleep-waking cycle. J Neurosci 25:6716-6720.

Li Y, van den Pol AN (2006) Differential target-dependent actions of coexpressed inhibitory dynorphin and excitatory hypocretin/orexin neuropeptides. J Neurosci 26:13037-13047.

Li Y, Gao XB, Sakurai T, van den Pol AN (2002) Hypocretin/Orexin excites hypocretin neurons via a local glutamate neuron-A potential mechanism for orchestrating the hypothalamic arousal system. Neuron 36:1169-1181.

Matsuki T, Nomiyama M, Takahira H, Hirashima N, Kunita S, Takahashi S, Yagami K, Kilduff TS, Bettler B, Yanagisawa M, Sakurai T (2009) Selective loss of $\mathrm{GABA}(\mathrm{B})$ receptors in orexin-producing neurons results in disrupted sleep/wakefulness architecture. Proc Natl Acad Sci U S A 106:4459-4464.

Mileykovskiy BY, Kiyashchenko LI, Siegel JM (2005) Behavioral correlates of activity in identified hypocretin/orexin neurons. Neuron 46:787-798.

Nagel G, Szellas T, Huhn W, Kateriya S, Adeishvili N, Berthold P, Ollig D, Hegemann P, Bamberg E (2003) Channelrhodopsin-2, a directly lightgated cation-selective membrane channel. Proc Natl Acad Sci U S A 100:13940-13945.

Nishino S, Ripley B, Overeem S, Lammers GJ, Mignot E (2000) Hypocretin (orexin) deficiency in human narcolepsy. Lancet 355:39-40.

Petreanu L, Huber D, Sobczyk A, Svoboda K (2007) Channelrhodopsin-2assisted circuit mapping of long-range callosal projections. Nat Neurosci 10:663-668.

Peyron C, Tighe DK, van den Pol AN, de Lecea L, Heller HC, Sutcliffe JG, Kilduff TS (1998) Neurons containing hypocretin (orexin) project to multiple neuronal systems. J Neurosci 18:9996-10015.

Sakurai T (2007) The neural circuit of orexin (hypocretin): maintaining sleep and wakefulness. Nat Rev Neurosci 8:171-181.

Saper CB, Scammell TE, Lu J (2005) Hypothalamic regulation of sleep and circadian rhythms. Nature 437:1257-1263.

Sasaki K, Suzuki M, Mieda M, Tsujino N, Roth B, Sakurai T (2011) Pharmacogenetic modulation of orexin neurons alters sleep/wakefulness states in mice. PloS One 6:e20360.

Schöne C, Venner A, Knowles D, Karnani MM, Burdakov D (2011) Dichotomous cellular properties of mouse orexin/hypocretin neurons. J Physiol 589:2767-2779.

Tecuapetla F, Patel JC, Xenias H, English D, Tadros I, Shah F, Berlin J, Deisseroth K, Rice ME, Tepper JM, Koos T (2010) Glutamatergic signaling by mesolimbic dopamine neurons in the nucleus accumbens. J Neurosci 30:7105-7110.

Thannickal TC, Moore RY, Nienhuis R, Ramanathan L, Gulyani S, Aldrich M, Cornford M, Siegel JM (2000) Reduced number of hypocretin neurons in human narcolepsy. Neuron 27:469-474.

Torrealba F, Yanagisawa M, Saper CB (2003) Colocalization of orexin a and glutamate immunoreactivity in axon terminals in the tuberomammillary nucleus in rats. Neuroscience 119:1033-1044.

Tsunematsu T, Kilduff TS, Boyden ES, Takahashi S, Tominaga M, Yamanaka A (2011) Acute optogenetic silencing of orexin/hypocretin neurons induces slow-wave sleep in mice. J Neurosci 31:10529-10539.

Williams RH, Alexopoulos H, Jensen LT, Fugger L, Burdakov D (2008) Adaptive sugar sensors in hypothalamic feeding circuits. Proc Natl Acad Sci U S A 105:11975-11980.

Williams RH, Morton AJ, Burdakov D (2011) Paradoxical function of orexin/hypocretin circuits in a mouse model of Huntington's disease. Neurobiol Dis 42:438-445.

Yamanaka A, Tsujino N, Funahashi H, Honda K, Guan JL, Wang QP, Tominaga M, Goto K, Shioda S, Sakurai T (2002) Orexins activate histaminergic neurons via the orexin 2 receptor. Biochemical and biophysical research communications 290:1237-1245.

Yizhar O, Fenno LE, Davidson TJ, Mogri M, Deisseroth K (2011) Optogenetics in neural systems. Neuron 71:9-34. 